\title{
Neuropilin-1 and neuropilin-2 are differentially expressed in human proteinuric nephropathies and cytokine-stimulated proximal tubular cells
}

\author{
Herbert Schramek ${ }^{1}$ Rita Sarközi ${ }^{1}$, Christina Lauterberg$^{2}$, Andreas Kronbichler ${ }^{1}$, Markus Pirklbauer $^{1}$, \\ Rudolf Albrecht ${ }^{1}$, Susie-Jane Noppert ${ }^{1}$, Paul Perco ${ }^{3}$, Michael Rudnicki ${ }^{1}$, Frank M Strutz ${ }^{2}$ and Gert Mayer ${ }^{1}$
}

Neuropilin-1 (NRP1) and neuropilin-2 (NRP2) are transmembrane glycoproteins with large extracellular domains that interact with class 3 semaphorins, vascular endothelial growth factor (VEGF) family members, and ligands, such as hepatocyte growth factor, platelet-derived growth factor BB, transforming growth factor- $\beta 1$ (TGF- $\beta 1$ ), and fibroblast growth factor2 (FGF2). Neuropilins (NRPs) have been implicated in tumor growth and vascularization, as novel mediators of the primary immune response and in regeneration and repair; however, their role in renal pathophysiology is largely unknown. Here, we report upregulation of tubular and interstitial NRP2 protein expression in patients with focal segmental glomerulosclerosis (FSGS). In an additional cohort of patients with minimal change disease (MCD), membranous nephropathy (MN), and FSGS, elevated NRP2 mRNA expression in kidney biopsies inversely correlated with estimated glomerular filtration rate (eGFR) at the time of biopsy. Furthermore, upregulation of NRP2 mRNA correlated with post-bioptic decline of kidney function. Expression of NRP1 and NRP2 in human proximal tubular cells (PTCs) was differentially affected after stimulation with TGF- $\beta 1$, interleukin- $1 \beta(\mathrm{IL}-1 \beta)$, and oncostatin $\mathrm{M}(\mathrm{OSM})$. Although the pro-fibrotic mediators, TGF- $\beta 1$ and IL- $1 \beta$, induced upregulation of NRP2 expression but downregulation of NRP1 expression, OSM stimulated the expression of both NRP1 and NRP2. Basal and OSM-induced NRP1 mRNA expression, as well as TGF- $\beta 1$-induced NRP2 mRNA and protein expression were partially mediated by MEK1/2-ERK1/2 signaling. This is the first report suggesting a differential role of NRP1 and NRP2 in renal fibrogenesis, and TGF- $\beta 1$, IL-1 $\beta$, and OSM represent the first ligands known to stimulate NRP2 expression in mammalian cells.

Laboratory Investigation (2009) 89, 1304-1316; doi:10.1038/labinvest.2009.96; published online 7 September 2009

KEYWORDS: tubulointerstitial fibrosis; FSGS; neuropilin; TGF- $\beta 1$; oncostatin M; proximal tubular epithelial cell

In contrast to the well-studied neuronal and vascular system, neuropilin (NRP) expression in cells of epithelial origin has received little attention so far. As epithelial cells in the breast, uterus, endometrium, kidney, and lung do express neuropilin-1 (NRP1), it is not surprising that tumors of epithelial origin show strong expression of this NRP isoform. ${ }^{1,2}$ NRP1 is highly expressed in carcinoma cell lines, such as prostatic and breast carcinoma cells, transitional cell, and renal cell carcinoma cells. ${ }^{3}$ In contrast, neoplasms of non-epithelial origin, such as human melanoma cells or human glioblastoma cells, show little NRP1 expression but high neuropilin-2 (NRP2) expression. ${ }^{3}$ NRP2 has recently been shown to have a critical and direct role in colorectal carcinoma tumor progression and may represent a potential therapeutic target for cancers in which it is expressed. ${ }^{4}$ Very little information is available regarding NRP expression and its regulation in renal tubular epithelial cells. NRP1 mRNA and protein expression has been detected in whole kidney, single and sieved glomeruli, as well as in cultured visceral glomerular epithelial cells. ${ }^{5}$ Furthermore, mRNA expression of NRP1 and NRP2 was observed in immortalized murine inner medullary collecting duct cells and mouse proximal tubular cells (PTCs). ${ }^{6}$ In these tubular epithelial cells, vascular endothelial growth factor (VEGF)-induced branching morphogenesis and tubulogenesis was VEGFR2- and NRP1dependent, suggesting that, in addition to endothelial vas-

\footnotetext{
${ }^{1}$ Department of Internal Medicine IV, Nephrology and Hypertension, Innsbruck Medical University, Innsbruck, Austria; ${ }^{2}$ Department of Nephrology and Rheumatology, Georg-August-University Medical Center, Göttingen, Germany and ${ }^{3}$ Emergentec Biodevelopment GmbH, Vienna, Austria

Correspondence: Dr H Schramek, MD, Department of Internal Medicine IV, Nephrology and Hypertension, Innsbruck Medical University, Anichstrasse 35, A-6020 Innsbruck, Austria.

E-mail: herbert.schramek@i-med.ac.at

Received 29 December 2008; revised 2 June 2009; accepted 23 July 2009
} 
culogenesis, VEGF can induce renal epithelial cell morphogenesis in a NRP1-dependent fashion. ${ }^{6}$ Very recently it has been shown that advanced glycation end-products suppress NRP1 expression in podocytes, and that NRP1 expression is decreased in glomeruli of diabetic $d b / d b$ mice when compared with their nondiabetic littermates. ${ }^{7}$ Finally, transcripts of both NRPs were found to be decreased in renal biopsies from patients with diabetic nephropathy compared with transplant donors. ${ }^{7}$

Here, we studied expression of NRP1 and NRP2 in tissue sections of patients with focal segmental glomerulosclerosis (FSGS) and different levels of tubulointerstitial fibrosis, as well as in human PTCs stimulated with the pro-fibrotic mediators transforming growth factor- $\beta 1$ (TGF- $\beta 1$ ) and interleukin- $1 \beta$ (IL-1 $\beta)$. Immunofluorescence analysis of FSGS tissue showed upregulation of tubular and interstitial NRP2 expression in fibrotic kidneys. In an additional cohort of patients with minimal change disease (MCD), membranous nephropathy (MN), and FSGS, elevated NRP2 mRNA expression in kidney biopsies correlated with post-bioptic decline of kidney function. Furthermore, the pro-fibrotic mediators, TGF- $\beta 1$ and IL- $1 \beta$, induced upregulation of NRP2 expression but downregulation of NRP1 expression, whereas the interleukin-6 family member oncostatin $\mathrm{M}$ (OSM) stimulated expression of both NRP1 and NRP2. Basal and OSM-stimulated NRP1 mRNA expression, as well as TGF- $\beta 1$-induced NRP2 expression was partially U0126- and $\mathrm{Cl}-1040$-sensitive, suggesting that the MEK1/2-ERK1/2 signaling module is involved in these effects. Together, these results suggest a differential role of NRP1 and NRP2 in human renal fibrogenesis and represent the first description of ligands, such as TGF- $\beta 1, \mathrm{IL}-1 \beta$, and OSM, which are able to stimulate NRP2 expression in mammalian cells.

\section{MATERIALS AND METHODS Reagents}

Cell culture reagents were obtained from Gibco (Life Technologies, Lofer, Austria). U0126 was purchased from Calbiochem (Nottingham, UK) and $\mathrm{Cl}-1040$ was kindly provided by P Cohen (MRC Protein Phosphorylation Unit, University of Dundee, Dundee, UK). Recombinant human OSM was obtained from Sigma (St Louis, MO, USA), whereas recombinant human TGF- $\beta 1$ and recombinant human IL- $1 \beta$ were purchased from R\&D Systems. All other reagents were obtained from Sigma.

\section{Cell Culture}

Human PTCs human kidney-2 (HK-2) were cultured in Keratinocyte-Serum Free Medium (KSFM) containing 10\% fetal bovine serum (FBS), $5 \mathrm{ng} / \mathrm{ml}$ recombinant epidermal growth factor (rEGF), $0.05 \mathrm{mg} / \mathrm{ml}$ bovine pituitary extract, $100 \mathrm{units} / \mathrm{ml}$ penicillin, and $100 \mu \mathrm{g} / \mathrm{ml}$ streptomycin. ${ }^{8-10}$ The cells (passages $20-30$ ) were grown at $37^{\circ} \mathrm{C}$ in a humidified $5 \% \mathrm{CO}_{2}$ atmosphere, and split at a 1:10 ratio, once a week. After growth to a subconfluent state, cells were washed once, made quiescent by incubation in serum- and supplementfree medium for $48 \mathrm{~h}$, and then used for experiments. Stimulations with ligands, such as OSM, TGF- $\beta 1$ and IL- $1 \beta$, or combinations thereof were performed in the absence of serum and any other growth supplements.

\section{Western Blot Analysis}

Cells were washed with ice-cold phosphate buffered saline (PBS) and lysed in $1 \times$ Laemmli buffer. ${ }^{10}$ For the examination of ERK1/2 phosphorylation and ERK2 protein expression, cells were lysed in ice-cold RIPA lysis buffer as described previously. ${ }^{10}$ Insoluble material was removed by centrifugation at $12000 \mathrm{~g}$ for $15 \mathrm{~min}$ at $4^{\circ} \mathrm{C}$. The protein concentrations were determined using a microbicinchoninic acid assay (Pierce) or Coomassie protein assay (Pierce) with BSA as a standard. Cell lysates were matched for protein, separated by $10 \%$ SDS-PAGE, and transferred to a polyvinylidene difluoride microporous membrane. Subsequently, membranes were probed with one of the following specific antibodies: anti-NRP1 (A-12) mouse monoclonal antibody, anti-NRP2 (C-9) mouse monoclonal antibody, anti-ERK2 (C-14) goat polyclonal antibody (all from Santa Cruz Biotechnology, Santa Cruz, CA, USA), anti- $\beta$-actin mouse monoclonal antibody (Sigma), anti-phospho-p44/42 MAPK (ERK1/2) Thr202/Tyr204 rabbit polyclonal antibody (Cell Signaling Technology, Beverly, MA, USA). After extensive washing of the sheets in TBS, $0.1 \%$ Tween-20, the primary antibodies were detected using horseradish peroxidaseconjugated goat anti-mouse IgG, rabbit anti-goat IgG, or goat anti-rabbit IgG (all from Santa Cruz Biotechnology), and visualized by ECL Plus Western Blotting Detection system (GE Healthcare, Buckinghamshire, UK) or by LumiGLO Western Blot Detection system (Cell Signaling Technology).

\section{Renal Biopsies}

We used 20 kidney biopsies obtained from patients with nephrotic kidney diseases during their routine diagnostic workup for which we had sufficient clinical follow-up data (Table 3). The histological diagnoses were $\mathrm{MCD}(n=8), \mathrm{MN}$ $(n=7)$, and FSGS $(n=5)$. Renal function was assessed at two time points by calculating the estimated glomerular filtration rate (eGFR) using the MDRD formula. The median followup time was 25 months (12-32 months). Patients were defined stable $(n=13)$ when eGFR was $>60 \mathrm{ml} / \mathrm{min} / 1.73 \mathrm{~m}^{2}$ at both time points, or when eGFR was $<60 \mathrm{ml} / \mathrm{min} / 1.73 \mathrm{~m}^{2}$ at either time point, and $\Delta$ eGFR was higher than $-1 \mathrm{ml} / \mathrm{min} /$ $1.73 \mathrm{~m}^{2}$ per year. Patients were defined as progressive $(n=7)$ when eGFR was $>60 \mathrm{ml} / \mathrm{min} / 1.73 \mathrm{~m}^{2}$ at the time of biopsy and $<60 \mathrm{ml} / \mathrm{min} / 1.73 \mathrm{~m}^{2}$ during follow-up, or when eGFR was $<60 \mathrm{ml} / \mathrm{min} / 1.73 \mathrm{~m}^{2}$ at both time points and $\Delta \mathrm{eGFR}$ was $<-1 \mathrm{ml} / \mathrm{min} / 1.73 \mathrm{~m}^{2}$ per year, or when they reached end-stage renal disease. RNA was isolated using Qiagen RNeasy Mini kit (Qiagen, Valencia, CA, USA), the samples were preamplified using TaqMan PreAmp Master Mix (Ambion, Austin, TX, USA) together with the respective 
TaqMan probes (vide infra) for $\sim 400$-fold amplification of the original RNA. The accuracy of this amplification method was tested, and we did not find any amplification bias (data not shown). In all biopsy real-time PCR experiments, we used PPIA (cyclophilin A; Hs99999904_ml) as an endogenous control. The use of surplus material for research purposes after routine diagnostic workup was approved by the Institutional Review Board of the Innsbruck Medical University.

\section{RNA Isolation and Real-Time PCR Analysis}

Total cellular RNA was extracted using TRI Reagent (Molecular Research Center, Cincinnati, OH, USA). ${ }^{9}$ RNA quantity was estimated by spectrophotometric analysis. Reverse transcription was carried out in $20 \mu \mathrm{l}$ volume using $2 \mu \mathrm{g}$ total RNA, $1 \mu \mathrm{M}$ random hexanucleotides as primer (Roche Diagnostics, Indianapolis, IN, USA), and Omniscript Reverse Transcriptase (Qiagen) according to the manufacturer's instructions. The reaction was carried out in RNase-free condition at $37^{\circ} \mathrm{C}$ for $60 \mathrm{~min}$ and heated at $93^{\circ} \mathrm{C}$ for $5 \mathrm{~min}$ to inactivate RTase. The cDNA was stored at $-20^{\circ} \mathrm{C}$ until use in TaqMan Gene Expression Assays (Applied Biosystems).

PCR was carried out using $2 \mu \mathrm{l}$ of cDNA template from the RT reaction, $1 \times$ TaqMan Universal PCR Master Mix containing dNTPs, AmpErase UNG, and AmpliTaq Gold DNA polymerase (Applied Biosystems), and premade TaqMan Gene Expression Assay Mix consisting of FAM dye-labeled TaqMan MGB probe and unlabeled PCR primers for human NRP1 (Hs00826129_m1), for human NRP2 (Hs00187290_m1), or for human VEGF-A (Hs00173626_m1), respectively (Applied Biosystems). ${ }^{9}$ Thermal cycler conditions were as follows: $50^{\circ} \mathrm{C}$ for $2 \mathrm{~min}$ and $95^{\circ} \mathrm{C}$ for $10 \mathrm{~min}$, followed by 45 cycles of amplification at $95^{\circ} \mathrm{C}$ for $15 \mathrm{~s}$ and $60^{\circ} \mathrm{C}$ for $1 \mathrm{~min}$. All reactions were run in duplicate. Each amplification experiment was carried out in a 96-well PCR plate on an ABI 7500 Sequence Detection System. All cellular RNA samples were normalized based on the TaqMan Gene Expression Assays for human GAPDH (Hs999999905_m1). Relative changes in gene expression (fold change) were calculated using the $2^{-\Delta \Delta C T}$ method.

\section{Indirect Immunofluorescence}

Human PTCs were grown to subconfluence on chamber slides (Lab-tek) and starved for $24 \mathrm{~h}$. Next, cells were stimulated with TGF- $\beta 1$ at a concentration of $10 \mathrm{ng} / \mathrm{ml}$ for 24 , 48 , and $72 \mathrm{~h}$. Controls were grown in regular DMEM medium. After the end of the stimulation period, cells were washed three times with PBS and fixed with methanol/acetone (1:1) at $-20^{\circ} \mathrm{C}$ for $20 \mathrm{~min}$. Cells were subsequently washed three times with PBS, and blocked with $1 \%$ BSA in PBS for $1 \mathrm{~h}$. Wells were incubated with the anti-NRP1 or anti-NRP2 antibody (at a concentration of $1: 25$ ) for $1 \mathrm{~h}$ at $37^{\circ} \mathrm{C}$, washed three times with PBS, and incubated with the rhodamineconjugated Fab secondary antibody (dilution 1:100, Chemicon, Hofheim, Germany) for $1 \mathrm{~h}$ at $37^{\circ} \mathrm{C}$. Nuclei were counterstained with DAPI (dilution 1:1000 of a stock of $1 \mathrm{mg} / \mathrm{ml}$ ).
After washing three times with PBS, cells were mounted by DAKO fluorescence mounting medium (DAKO, Hamburg, Germany). Visualization was performed using an Olympus IX10 fluorescence microscope.

For NRP1 and NRP2 expression studies in renal tissue, eight kidney sections from biopsies from patients with FSGS and variable degrees of tubulointerstitial fibrosis were stained. Kidney sections from non-tumor parts of tumor nephrectomies served as controls. Stainings were performed by indirect immunofluorescence. Briefly, paraffin sections were deparaffinized followed by blocking with $3 \% \mathrm{H}_{2} \mathrm{O}_{2}$ for $15 \mathrm{~min}$. Incubation with the primary antibodies (anti-NRP1 and anti-NRP2, both 1:200) was followed by incubation with the Rhodamine-labeled secondary antibody (Chemicon) at a dilution of 1:500. Before analysis, nuclei were counterstained with DAPI (dilution of $1: 1000$ of a $1 \mathrm{mg} / \mathrm{ml}$ stock solution). Specificity of antibody labeling was shown by the lack of staining after substituting proper control immunoglobulins for the primary antibodies. Slides were mounted with DAKO fluorescent mounting medium (DAKO) and images were visualized using an Olympus IX10 fluorescence microscope. Tubular stainings were classified by two independent investigators who had been blinded for the diagnosis and staining performed as negative $(\varnothing)$, positivity in $<25 \%$ of tubuli $(+)$, staining of $25-50 \%$ of tubuli $(++)$, and positivity of $>50 \%$ of tubuli $(+++)$. In addition, staining patterns were noted. The use of kidney biopsies for research purposes was approved by the local ethics committee of the University of Goettingen, and written consent was obtained from all patients before biopsy.

\section{Statistical Analyses}

Pearson's $\mathrm{R}$ and a two-tailed $t$-test were used for calculation of correlation between real-time PCR results of NRP1 and NRP2 mRNA expression in the renal biopsies, the eGFR at the time of biopsy, and the decline of eGFR during follow-up, respectively. Two-tailed $t$-tests were used to assess the significance of differences of ligand and inhibitor administration on the mRNA expression in human PTC when compared with untreated cells. Fold alterations in mRNA levels are expressed as mean \pm s.e.m.

\section{RESULTS \\ Upregulation of Endoluminal and Interstitial NRP2 Expression in Human FSGS}

As preliminary real-time PCR analyses of microdissected PTC obtained from patients with a progressive loss of kidney function revealed alterations in NRP expression, we decided to carry out immunofluorescence analysis of NRP1 and NRP2 expression in tissue sections from FSGS patients $(n=8)$ with variable degrees of tubulointerstitial fibrosis when compared with expression levels in normal control kidneys $(n=3)$. Clinical characteristics of FSGS patients and controls are summarized in Table 1. As depicted in Figure 1b, basal NRP1 protein expression in control kidneys was 
Table 1 Characteristics of patients and controls

\begin{tabular}{|c|c|c|c|c|c|c|}
\hline & Diagnosis & Gender & Age (years) & S-Creatinin (mg/dl) & Proteinuria $(\mathrm{g} / 24 \mathrm{~h})$ & Interstitial fibrosis \\
\hline Control 1 & Normal kidney & Male & 61 & 0.8 & $\varnothing$ & $\varnothing$ \\
\hline Control 3 & Normal kidney & Female & 71 & 1.1 & $\varnothing$ & $\varnothing$ \\
\hline Patient 1 & FSGS & Male & 58 & 2.1 & 1.7 & $35 \%$ \\
\hline Patient 3 & FSGS & Female & 61 & 1.9 & 1.4 & $45 \%$ \\
\hline Patient 4 & FSGS & Female & 73 & 1.4 & 0.8 & $15 \%$ \\
\hline Patient 5 & FSGS & Male & 57 & 1.3 & 1.1 & $25 \%$ \\
\hline Patient 6 & FSGS & Female & 61 & 1.5 & 1.1 & $30 \%$ \\
\hline Patient 7 & FSGS & Female & 49 & 1.8 & 2.8 & $50 \%$ \\
\hline
\end{tabular}

FSGS, focal segmental glomerulosclerosis.
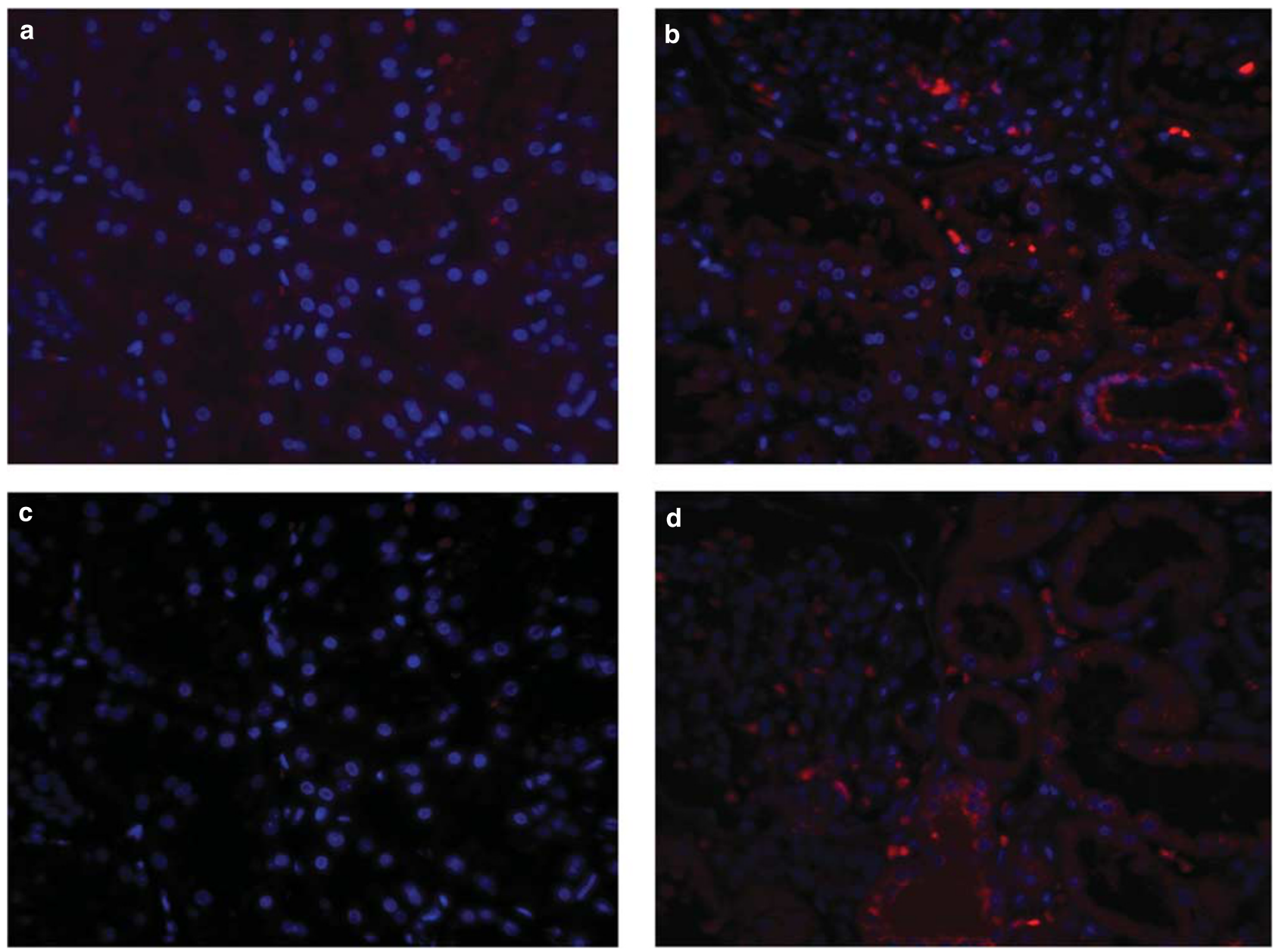

Figure 1 Indirect immunofluorescence staining of NRP1 and NRP2 protein expression in tissue sections of a normal human kidney. (a and b) Selected tubular epithelial cells show NRP1 expression (red) with a tendency towards staining at the apical side (b), when compared with negative controls (a). (c and d) Conversely, tubular NRP2 expression (red) seemed to be located more to the perinuclear cytoplasm (d). Panel c depicts the respective negative control. Nuclei were counterstained with DAPI (blue). Representative micrographs are depicted. Original magnification $\times 400$. 
detected in several tubular epithelial cells with a tendency towards staining of apical membrane domains. Conversely, tubular NRP2 expression seemed to be located more to the perinuclear cytoplasm (Figure 1d). Figures 1a and c show the respective negative-control stainings in normal adult human kidneys. In contrast, immunofluorescence analysis of FSGS tissue sections revealed robust upregulation of NRP2 expression in fibrotic kidneys with tubular endoluminal predominance (Figure 2c) and with increased interstitial staining (Figure 2d). Although tubular staining was mainly detected in PTC, interstitial staining seemed to be localized mainly to interstitial fibroblasts. Moreover, atrophic tubules and morphologically unchanged tubules displayed increased NRP2 staining. This increased NRP2 expression seemed to be associated with a tendency towards the downregulation of tubular NRP1 expression in FSGS kidneys when compared with control kidneys (Table 2). A semi-quantitative analysis of all the experiments in eight FSGS patients and three control kidneys is summarized in Table 2. These results suggest that the two NRP isoforms are differentially expressed in FSGS patients with variable degrees of tubulointerstitial fibrosis when compared with those of normal control kidneys.

\section{Increased NRP2 mRNA Expression in Nephrotic Kidney Diseases Correlates Inversely with eGFR at the Time of Biopsy and is Associated with Adverse Renal Prognosis} To validate these findings, we analyzed mRNA expression of NRP1 and NRP2 in 20 additional kidney biopsies from patients with nephrotic kidney diseases, such as MCD, MN, and FSGS (Table 3 and Figure 3). mRNA expression of NRP2, but not of NRP1, showed a significant correlation with renal function (expressed as eGFR) at the time of biopsy (Figure 3a). Patients with impaired renal function showed higher NRP2 mRNA expression, whereas patients with near normal renal function showed low NRP2 mRNA values (Figure 3a). Furthermore, we analyzed the correlation of NRP1 and NRP2 mRNA levels with the clinical follow-up of these patients. Although NRP1 mRNA showed higher expression in progressive patients when compared with stable nephrotic diseases, this difference did not reach significance (1.4-fold; $P=0.08)$. However, NRP2 was significantly upregulated in those patients who showed a decline of renal function during the median follow-up period of 25 months (1.7-fold; $P=0.04$ ) (Figure $3 b)$. These results suggest that an increased mRNA expression of NRP2, but not of NRP1, predicts poor renal outcome in various renal nephrotic pathologies already at the time of biopsy.

\section{The Pro-Fibrotic Mediators, TGF- $\beta 1$ and IL-1 $\beta$, Inhibit NRP1 Expression But Stimulate NRP2 Expression in Human Proximal Tubular Cells}

Among the many factors that regulate the renal fibrotic process, TGF- $\beta 1$ is one that have a central role. ${ }^{11-14}$ Other factors, such as IL- $1 \beta$, can regulate epithelial-mesenchymal transition (EMT) and fibrosis through modulation of TGF- $\beta 1$ expression or activity, ${ }^{15}$ or in the case of OSM, have potential to act as both a pro-EMT molecule and a pro-MET mediator. ${ }^{10}$ As human kidneys with various degrees of tubulointerstitial fibrosis showed robust upregulation of tubular and interstitial NRP2 protein expression, we investigated the effects of pro-fibrotic mediators TGF- $\beta 1$ and IL- $1 \beta$ when compared with OSM in human PTCs in culture. A $24 \mathrm{~h}$ stimulation of human PTC with TGF- $\beta 1(10 \mathrm{ng} / \mathrm{ml})$ or IL-1 $\beta(10 \mathrm{ng} / \mathrm{ml})$ led to a partial inhibition of NRP1 mRNA expression and a strong induction of NRP2 mRNA levels (Figure 4a). When compared with unstimulated controls, TGF- $\beta 1$ - and IL- $1 \beta$-induced NRP2 mRNA expression was 4.8 -fold and 3.5 -fold, respectively $(n=4 ; P<0.01)$. In contrast, $10 \mathrm{ng} / \mathrm{ml}$ OSM stimulated both NRP1 and NRP2 mRNA expression 1.8- and 2.2-fold, respectively (Figure 4a; $n=4, P<0.01)$. All three cytokines of interest induced VEGF-A mRNA expression in human PTC after $24 \mathrm{~h}$ (Figure 4a). These results from real-time PCR were verified by western blot analysis. After $48 \mathrm{~h}$ of incubation, TGF- $\beta 1$ and IL- $1 \beta$ inhibited NRP1 protein expression but stimulated NRP2 protein expression (Figure $4 \mathrm{~b}$ ), whereas OSM increased both NRP1 and NRP2 protein levels (Figure 4b). Administration of IL- $1 \beta$ together with TGF- $\beta 1$ revealed an additive inhibitory effect on NRP1 protein expression (data not shown). The effects of TGF- $\beta 1$ and IL- $1 \beta$ on NRP1 and NRP2 mRNA expression were time dependent. TGF- $\beta 1$ mediated inhibition of NRP1 mRNA expression started after $12 \mathrm{~h}$ and reached significance after $48 \mathrm{~h}$ of incubation (Figure $5 \mathrm{a} ; n=5, P<0.05$ ). IL- $1 \beta$ led to a similar, albeit not significant tendency towards inhibition of NRP1 mRNA expression (Figure $5 \mathrm{a} ; n=5, P=0.056$ after $48 \mathrm{~h}$ of incubation). TGF- $\beta 1$ - and IL- $1 \beta$-stimulated NRP2 mRNA expression showed similar kinetics (Figure $5 \mathrm{~b}$ ) as did the OSMinduced VEGF-A mRNA expression (data not shown). After $48 \mathrm{~h}$ of stimulation, TGF- $\beta 1$ and IL- $1 \beta$ led to a $6.3-$ and a 3.2-fold increase in NRP2 mRNA expression, respectively (Figure $5 \mathrm{~b} ; n=5, P<0.01$ ). TGF- $\beta 1$-mediated effects on NRP1 and NRP2 protein expression showed a similar time dependence (Figure $5 \mathrm{c}$ ). Both TGF- $\beta 1$-inhibited NRP1 protein expression and TGF- $\beta 1$-stimulated NRP2 protein expression started as early as $6 \mathrm{~h}$ after incubation and showed

Figure 2 Indirect immunofluorescence staining of NRP1 and NRP2 protein expression in tissue sections of human kidneys with variable degrees of tubulointerstitial fibrosis. (a and b) Tubular NRP1 protein expression (red) in fibrotic kidneys. (c and d) Tubular NRP2 expression (red) showed robust upregulation in fibrotic kidneys and was located predominantly at the endoluminal side (c). In addition, increased interstitial NRP2 expression was observed (d). (e and f) Substitution of proper control immunoglobulins for the primary antibodies showed lack of specific staining. Nuclei were counterstained with DAPI (blue). Representative micrographs are depicted. Original magnification $\times 400$. 

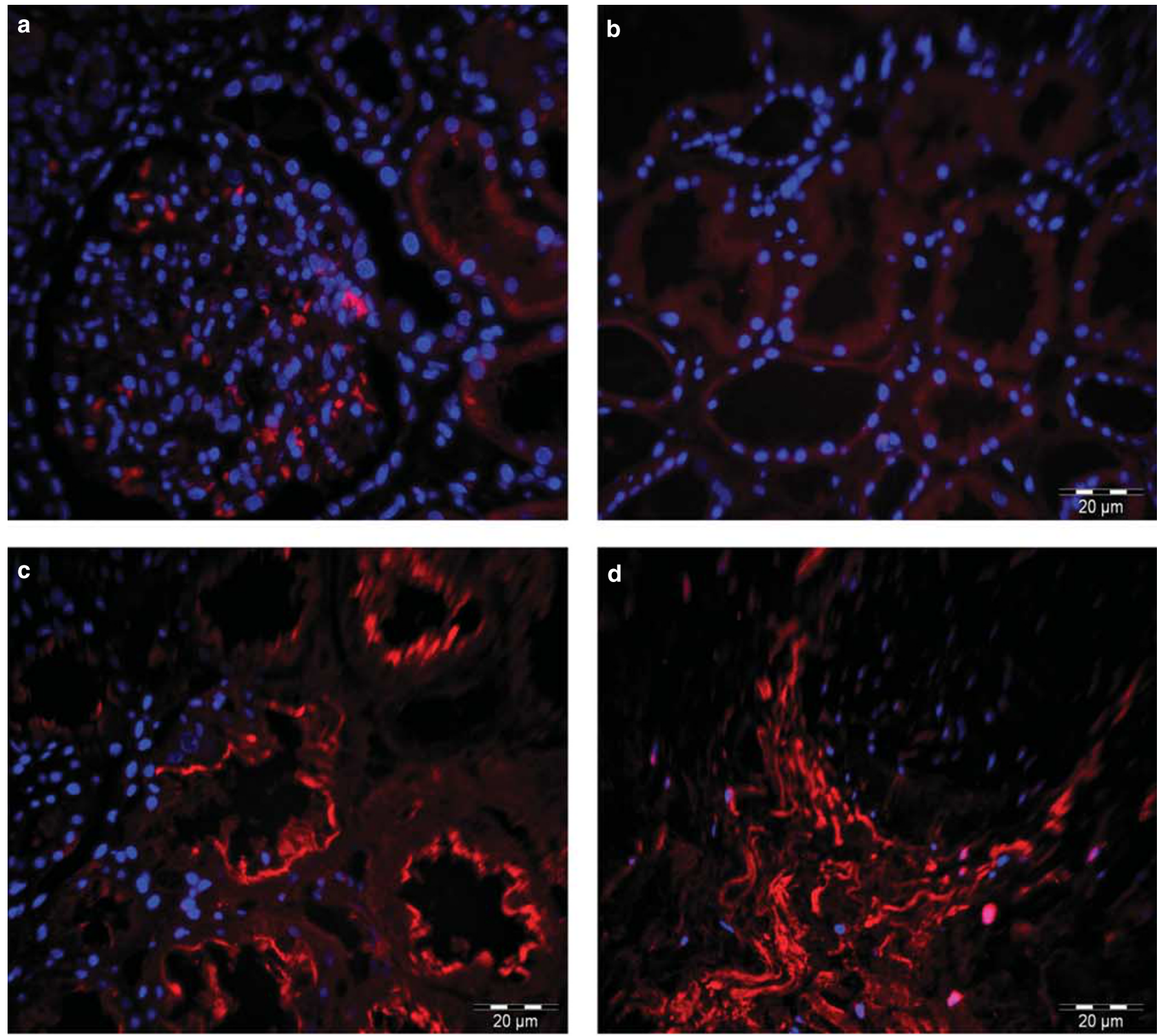

d
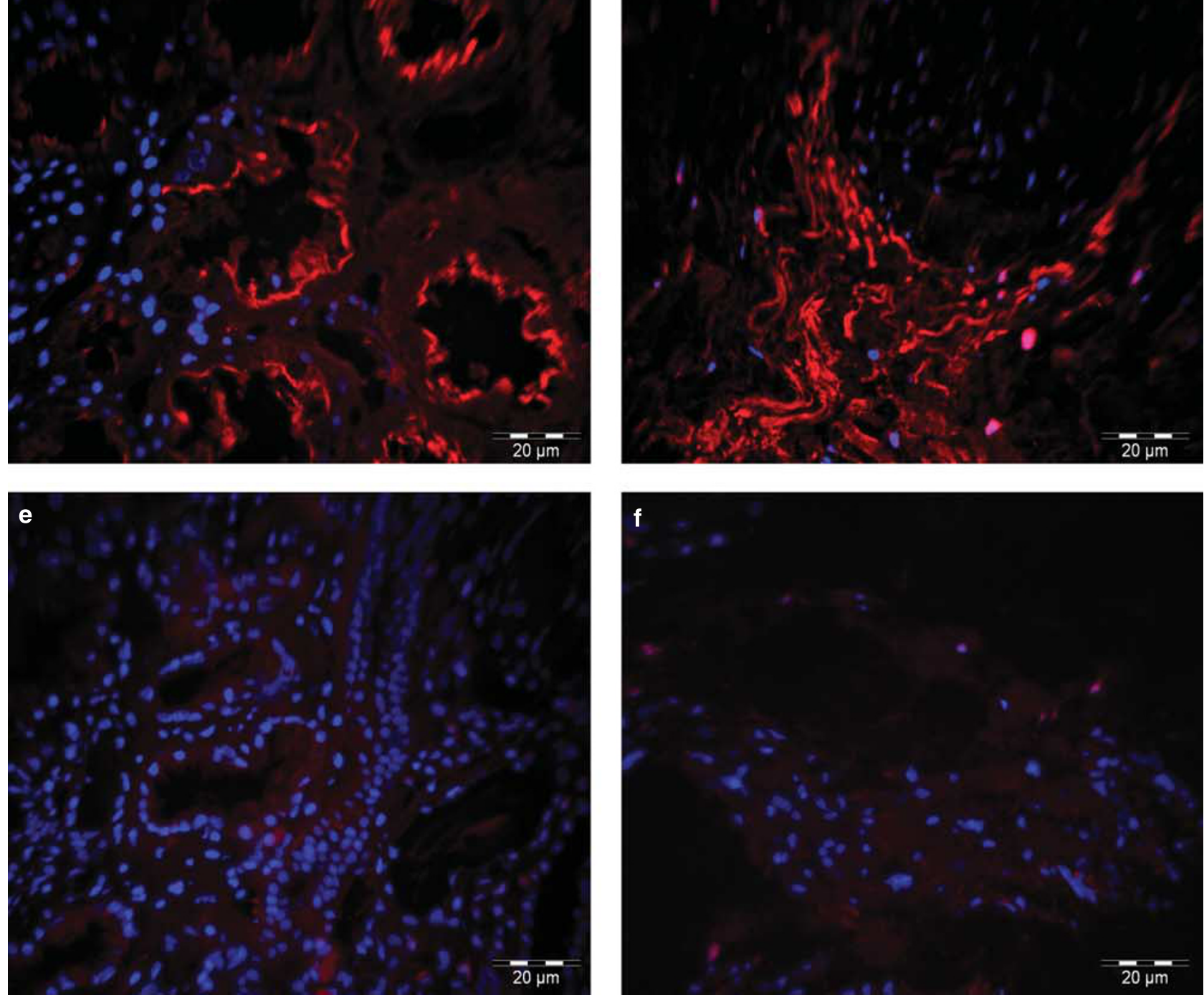

f

$\overline{20 \mu \bar{m}}$ 
Table 2 Degree of tubulointerstitial fibrosis and intensity of tubular NRP1 and NRP2 stainings

\begin{tabular}{lccc}
\hline Diagnosis & $\begin{array}{c}\text { Interstitial } \\
\text { fibrosis }\end{array}$ & $\begin{array}{c}\text { Tubular NRP1 } \\
\text { staining }\end{array}$ & $\begin{array}{c}\text { Tubular NRP2 } \\
\text { staining }\end{array}$ \\
\hline Control 1 & $\varnothing$ & +(endoluminal) & + (diffuse) \\
Control 2 & $\varnothing$ & + (endoluminal) & + (perinuclear) \\
Control 3 & $\varnothing$ & + (endoluminal) & + +(perinuclear) \\
FSGS & $35 \%$ & $(+)$ & ++ (endoluminal) \\
FSGS & $50 \%$ & $\varnothing$ & ++ (endoluminal) \\
FSGS & $45 \%$ & $\varnothing$ & + (endoluminal) \\
FSGS & $15 \%$ & $(+)$ & + (perinuclear) \\
FSGS & $25 \%$ & $\varnothing$ & + (perinuclear) \\
FSGS & $30 \%$ & $\varnothing$ & + +(diffuse) \\
FSGS & $50 \%$ & $\varnothing$ & ++ (endoluminal) \\
FSGS & $20 \%$ & $\varnothing$ & + (endoluminal) \\
\hline
\end{tabular}

FSGS, focal segmental glomerulosclerosis.

Owing to different stainings patterns, the respective predominant staining pattern is indicated in parenthesis. $\varnothing=$ negative, $(+)=$ weak, $+=$ positive, $++=$ robustly positive,$+++=$ highly positive.

a maximum effect after $48 \mathrm{~h}$. All together these results suggest that in human PTC in culture the two pro-fibrotic mediators, TGF- $\beta 1$ and IL- $1 \beta$, represent strong stimulators of NRP2 expression but inhibitors of NRP1 expression. In contrast, the IL-6 family member OSM seems to induce expression of both NRP2 and NRP1.

These results were corroborated by immunofluorescence studies showing that NRP2 was not detectable in human PTC in culture under basal conditions (Figure 6a) and that NRP1 expression was not inducible by stimulation with $10 \mathrm{ng} / \mathrm{ml}$ TGF- $\beta 1$ (Figure $6 \mathrm{~b}$ ). Conversely, the expression of NRP2 was inducible by TGF- $\beta 1$ in a time-dependent manner peaking after 48 (Figure 6c) and $72 \mathrm{~h}$ (Figure 6d). Interestingly, NRP2 expression was restricted almost exclusively to cells undergoing mitosis. In summary, TGF- $\beta 1$, IL- $1 \beta$, and OSM represent the first mediators known to affect NRP2 expression in mammalian cells. Moreover, these findings are the first evidence for a differential regulation of NRP1 and NRP2 mRNA expression in cytokine-stimulated renal tubular epithelial cells of human origin and support the idea of a differential role of both NRPs in renal tubulointerstitial fibrogenesis.

\section{TGF- $\beta 1$-Induced NRP2 mRNA and Protein Expression is MEK1/2-ERK1/2 Dependent}

In addition to the canonical Smad signaling pathways that are known to have a role in the regulation of cell growth, differentiation and TGF- $\beta$-induced EMT, Smad-independent TGF- $\beta$-regulated networks are known to include Ras-RafMEK-ERK signaling. ${ }^{16}$ Cooperative signaling between
TGF- $\beta 1$ and MEK1/2-ERK1/2 is required for the maintenance of complete EMT in various epithelial cell types, ${ }^{17,18}$ and OSM is a strong stimulator of the mitogen-activated protein kinases, ERK1, ERK2, and ERK5, in human PTC. ${ }^{10}$ Thus, we investigated the regulatory function of the intracellular signaling molecules ERK1 and ERK2 for NRP1 and NRP2 expression in OSM- when compared with TGF- $\beta 1$-stimulated human PTC. Preincubation of human PTC with $10 \mu \mathrm{M}$ of the synthetic MEK1/2 inhibitor U0126 slightly inhibited basal and OSM-induced NRP1 mRNA expression after $24 \mathrm{~h}(n=6, P<0.05)$, but did not affect TGF- $\beta 1$ - and IL- $1 \beta$-mediated inhibition of NRP1 mRNA expression (Figure 7a). In contrast, $10 \mu \mathrm{M}$ U0126 partially inhibited TGF- $\beta 1$-induced NRP2 mRNA expression in human PTC from a 3.85- \pm 0.35 -fold increase in the absence of U0126 to a 2.63- \pm 0.13 -fold increase in the presence of U0126 (Figure $7 \mathrm{~b} ; n=6, P<0.01$ ). Similar results were obtained using $1 \mu \mathrm{M}$ of the MEK $1 / 2$ inhibitor Cl-1040, which partially inhibited TGF- $\beta 1$-induced NRP2 protein expression without having an effect on basal NRP2 protein expression (Figure 7c). In parallel, the synthetic MEK1/2 inhibitor Cl-1040 (PD184352) completely inhibited ERK1/2 phosphorylation in the absence and in the presence of OSM or TGF- $\beta 1$ after $24 \mathrm{~h}$ of incubation without affecting ERK2 protein expression (Figure 7c). Furthermore, Cl-1040 inhibited rapid OSM-induced ERK1/2 phosphorylation after $10 \mathrm{~min}$ of stimulation (Figure 7c). At a concentration of $1 \mu \mathrm{M}, \mathrm{Cl}-1040$ has previously been reported to inhibit basal and EGF-induced ERK1/2 phosphorylation, but not ERK5 phosphorylation in human PTC. ${ }^{17}$ Thus, these results suggest that OSM-induced NRP1 mRNA expression and TGF- $\beta 1$ induced NRP2 mRNA and protein expression is partially mediated by MEK1/2-ERK1/2 signaling.

\section{DISCUSSION}

Our study shows four novel findings with respect to a pathophysiological role of NRP isoforms 1 and 2 and their regulation in human kidneys: (i) Tubular and interstitial NRP2 expression is upregulated in human FSGS kidneys with variable degrees of tubulointerstitial fibrosis. (ii) Increased NRP2 mRNA expression in separate kidney biopsies from patients with nephrotic kidney diseases correlates inversely with eGFR at the time of biopsy and is associated with adverse renal prognosis. (iii) NRP1 and NRP2 expression in human PTC is differentially affected by the pro-fibrotic cytokines TGF- $\beta 1$ and IL- $1 \beta$ when compared with the IL- 6 family member OSM. TGF- $\beta 1$ and IL- $1 \beta$ induce upregulation of NRP2 expression and downregulation of NRP1 expression in human PTC. (iv) OSM-stimulated NRP1 mRNA expression and TGF- $\beta 1$-stimulated NRP2 expression are U0126- and Cl-1040-sensitive suggesting that these effects are at least partially mediated by the MEK1/2-ERK1/2 signaling pathway.

NRP1 was originally identified as a neuronal cell surface protein. ${ }^{19}$ Subsequently, analysis of NRP1 transgenic and 
Table 3 Patients characteristics

\begin{tabular}{|c|c|c|c|c|c|c|c|c|c|c|}
\hline Subject no. & Diagnosis & Gender & Age (years) & $\begin{array}{c}\text { eGFR biopsy } \\
\left(\mathrm{ml} / \mathrm{min} / 1.73 \mathrm{~m}^{2}\right)\end{array}$ & $\begin{array}{l}\text { Proteinuria } \\
\text { biopsy (g/g) }\end{array}$ & $\begin{array}{l}\text { eGFR follow-up } \\
\left(\mathrm{ml} / \mathrm{min} / 1.73 \mathrm{~m}^{2}\right)\end{array}$ & $\begin{array}{c}\text { Proteinuria } \\
\text { follow-up (g/g) }\end{array}$ & $\begin{array}{l}\text { Follow-up } \\
\text { time(months) }\end{array}$ & $\begin{array}{c}\Delta \mathrm{eGFR} \\
(\mathrm{ml} / \mathrm{min} / \text { year) }\end{array}$ & $\begin{array}{l}\text { Interstitial } \\
\text { fibrosis }\end{array}$ \\
\hline \multicolumn{11}{|c|}{ Stable patients } \\
\hline NC16 & $\mathrm{MCD}$ & M & 31 & 77 & 7.0 & 92 & 0.1 & 24 & 7.6 & Mild \\
\hline NC17 & MCD & $\mathrm{F}$ & 56 & 109 & 17.0 & 134 & 0.0 & 30 & 9.7 & None \\
\hline NC18 & MCD & M & 41 & 77 & 1.3 & 78 & 0.6 & 27 & 0.4 & None \\
\hline NC19 & $M C D$ & M & 69 & 57 & 8.0 & 61 & 0.2 & 24 & 2.2 & Severe \\
\hline NC27 & pFSGS & $F$ & 26 & 115 & 2.9 & 132 & 0.1 & 24 & 8.4 & None \\
\hline NC43 & pFSGS & M & 31 & 55 & 4.4 & 55 & 2.2 & 25 & -0.2 & Severe \\
\hline NC56 & pFSGS & $\mathrm{F}$ & 42 & 85 & 1.8 & 77 & 5.4 & 26 & -3.5 & Mild \\
\hline NC70 & MCD & $\mathrm{F}$ & 31 & 113 & 5.8 & 85 & 3.7 & 25 & -13.5 & Mild \\
\hline NC76 & MCD & $\mathrm{F}$ & 53 & 43 & 9.6 & 58 & 0.0 & 25 & 7.5 & Mild \\
\hline NC81 & MCD & M & 20 & 136 & 2.2 & 112 & 0.1 & 12 & -23.1 & None \\
\hline NC82 & MCD & $\mathrm{F}$ & 54 & 81 & 11.3 & 86 & 0.9 & 23 & $2 . .9$ & Mild \\
\hline NC23 & $\mathrm{MN}$ & M & 71 & 63 & 3.4 & 65 & 0.2 & 24 & 0.8 & Mild \\
\hline $\mathrm{NC72}$ & $\mathrm{MN}$ & M & 53 & 87 & 8.7 & 77 & 1.9 & 25 & -4.8 & Moderate \\
\hline \multicolumn{11}{|c|}{ Progressive patients } \\
\hline NC42 & pFSGS & $\mathrm{F}$ & 20 & 47 & 1.7 & 40 & 0.4 & 32 & -2.8 & Mild \\
\hline NC44 & pFSGS & M & 43 & 57 & 4.5 & 41 & 5.4 & 26 & -7.5 & None \\
\hline NC39 & $\mathrm{MN}$ & $\mathrm{F}$ & 63 & 37 & 8.5 & 11 & 6.9 & 26 & -12.3 & Moderate \\
\hline NC51 & $\mathrm{MN}$ & M & 51 & 100 & 1.3 & 23 & 7.6 & 26 & -36.1 & Mild \\
\hline NC52 & $\mathrm{MN}$ & M & 71 & 68 & 2.5 & 31 & 2.4 & 25 & -18.0 & Mild \\
\hline NC73 & $\mathrm{MN}$ & $\mathrm{F}$ & 69 & 79 & 4.8 & 50 & 1.2 & 27 & -12.9 & Mild \\
\hline NC89 & $\mathrm{MN}$ & $\mathrm{F}$ & 63 & 154 & 3.0 & 31 & 1.0 & 22 & -65.7 & Mild \\
\hline
\end{tabular}

F, female; $M$, male.

MCD, minimal change disease; PFSGS, primary focal-segmental glomerulosclerosis; $\mathrm{MN}$, membranous nephropathy. Interstitial fibrosis was scored as none, mild $(<10 \%)$, moderate (10-30\%) and severe ( $>30 \%)$. We analyzed NRP1 and NRP2 mRNA expression in 20 kidney biopsies from patients with nephrotic kidney diseases. 

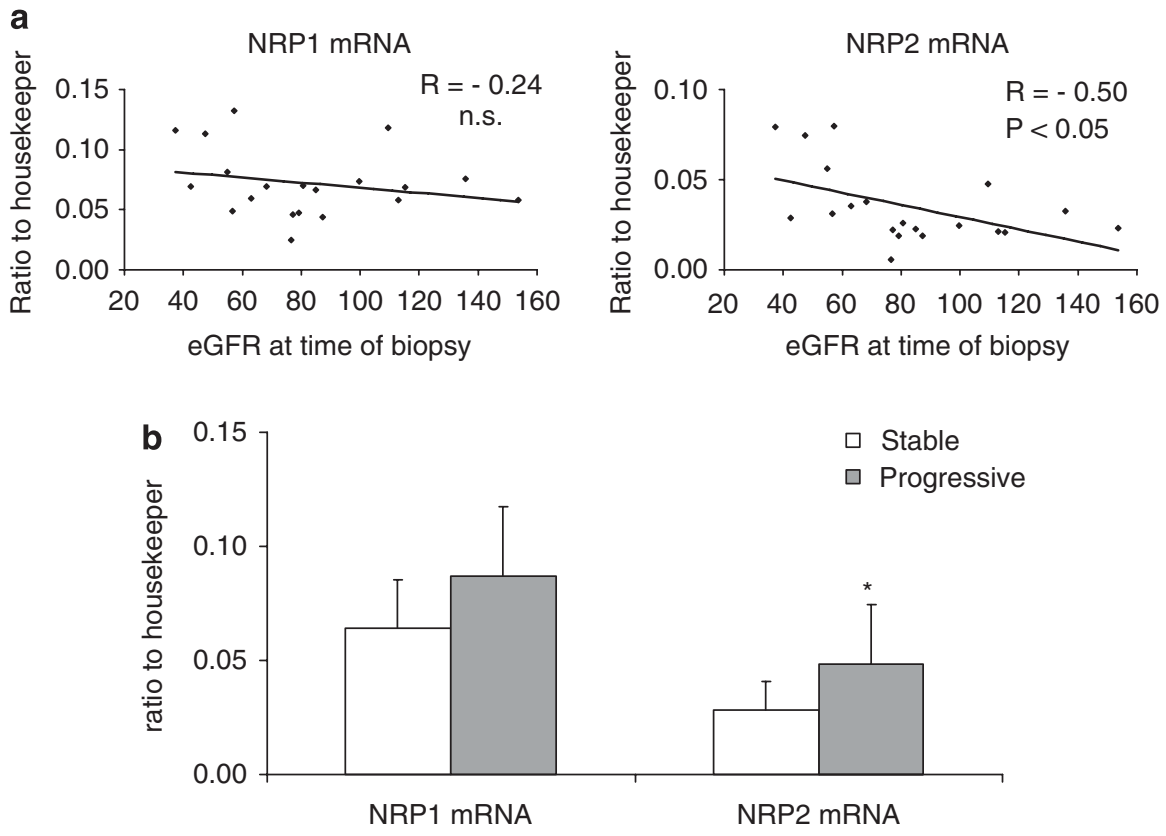

Figure 3 Real-time PCR analysis of renal biopsy material from patients with nephrotic kidney diseases. NRP1 and NRP2 mRNA expression values were calculated as ratio to the endogenous control PPIA (cyclophilin A). (a) mRNA expression of NRP2, but not of NRP1, showed a significant inverse correlation with renal function (expressed as eGFR) at time of biopsy. (b) Correlation of NRP1 and NRP2 mRNA levels with the clinical follow-up of these patients. Patients were defined as stable $(n=13)$ or progressive $(n=7)$ according to loss of eGFR during follow-up as described in section Materials and Methods. NRP1 mRNA expression showed a tendency to higher values in progressive patients $(P=0.08)$, whereas NRP2 mRNA was significantly $(P=0.04)$ upregulated in progressive patients $\left({ }^{*} P<0.05\right)$.

deficient mouse and zebrafish models established an essential role of NRP1 in the development of the embryonic nervous and cardiovascular systems. ${ }^{20-23}$ NRPs are also highly expressed in diverse tumor cell lines and human neoplasms and have been implicated in tumor growth and vascularization. ${ }^{2-4,24,25}$ More recently, it has been reported that NRP1 might have a role as a novel mediator of the primary immune response, as well as in tissue regeneration and repair. ${ }^{26}$ Together these findings suggest that NRPs are multifunctional co-receptors essential for neuronal and cardiovascular development, but potentially have additional functions in diverse physiological and disease-related settings. Thus, and on the basis of the preliminary real-time PCR analyses of microdissected proximal tubular cells from patients with a progressive loss of kidney function, it was of interest to us to study the expression of the two NRP isoforms in renal tissue sections of patients suffering from FSGS. Interestingly, these experiments revealed reduced luminal NRP1 expression associated with the upregulation of endoluminal and interstitial NRP2 expression in human FSGS. These results were corroborated by the finding of an inverse correlation of increased NRP2 mRNA expression with impaired renal function at the time of biopsy and with adverse renal outcome in various nephrotic kidney diseases, such as MCD, MN, and FSGS. Hence, an increased expression of NRP2 mRNA may predict poor renal outcome in renal nephrotic pathologies already at time of biopsy.
Clinical studies suggest that NRP1 has a role in tumor growth and disease progression. ${ }^{3,25,27}$ Overexpression of NRP1 has been shown to be positively associated with the metastatic potential, advanced stage, and clinical grade of prostate carcinoma. ${ }^{28}$ NRP1 upregulation in gastrointestinal carcinomas seems to correlate with invasive behavior and metastatic potential. ${ }^{29}$ Co-expression of NRP1 and NRP2 also increased in the progression from dysplasia to microinvasive lung carcinoma, and correlated significantly with tumor progression and poor prognosis in patients with nonsmall-cell lung carcinoma. ${ }^{30}$ Although most studies have indicated a pro-tumorigenic role of NRPs, some reports suggest that NRP1 has a more complex role in some tumor types. NRP1 overexpression in Panc-1 cells was found to reduce tumor volume and incidence, ${ }^{31}$ and there is also evidence pointing to potentially differential or antagonistic roles of NRP1 and NRP2 in tumor cell regulation. ${ }^{27}$ In agreement with murine studies, data from human surgical wounds indicate endothelial NRP1 upregulation early in the wound-healing process, that is, by 2 weeks after injury. ${ }^{26}$ Thereafter, NRP1 expression is downregulated as tissue repair continues. To date there is no evidence that NRP2 has a role in wound healing. ${ }^{26}$

In contrast to these reports, very little is known about a possible physiological or pathophysiological role of NRPs in the kidney. In embryonic rat and mouse kidneys, NRP1 and especially NRP2 are several fold more abundant than in 


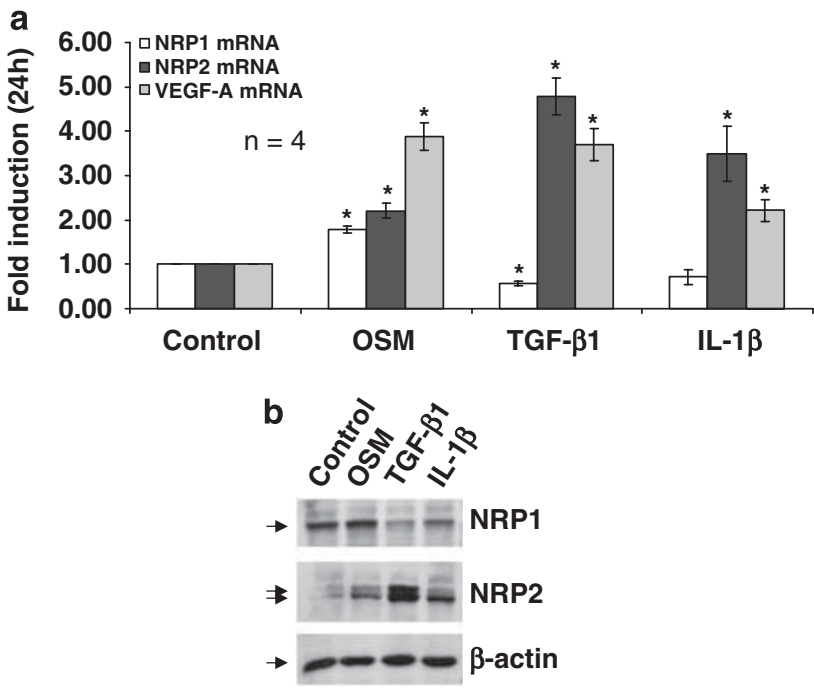

Figure 4 Differential effects of OSM, TGF- $\beta 1$, and IL- $1 \beta$ on the expression of NRP1, NRP2, and VEGF-A in human PTC. Cells were serum- and supplementstarved for $48 \mathrm{~h}$, and were then stimulated with $10 \mathrm{ng} / \mathrm{ml}$ OSM, TGF- $\beta 1$ or IL- $1 \beta$ for the indicated periods of time. (a) OSM-, TGF- $\beta 1$-, and IL- $1 \beta$-induced effects on gene expression of NRP1, NRP2, and VEGF-A after $24 \mathrm{~h}$ of incubation ( ${ }^{*} P<0.01$ compared with controls). cDNAs from $n=4$ independent RNA isolations were applied for real-time PCR analysis. Data are presented as fold induction above NRP1, NRP2, and VEGF-A mRNA control levels after normalizing to GAPDH expression. Each data point indicates the average of four independent experiments with error bars corresponding to s.e.m. (b) OSM-, TGF- $\beta 1$-, and IL-1 $\beta$-induced effects on NRP1, NRP2, and $\beta$-actin protein expression after $48 \mathrm{~h}$ of incubation. Protein matched samples of stimulated cells and unstimulated controls were separated on SDS-PAGE and analyzed by western immunoblot for protein expression of NRP1, NRP2, and $\beta$-actin. The results from one representative western blot of $n=4$ separate experiments are depicted.

newborn or adult kidneys. ${ }^{32}$ In immortalized murine inner medullary collecting duct cells, and mouse PTC, VEGF-induced branching morphogenesis and tubulogenesis was VEGFR2- and NRP1-dependent, suggesting that, in addition to endothelial vasculogenesis, VEGF might induce renal epithelial cell morphogenesis in a NRP1-dependent manner. ${ }^{6}$ Furthermore, a significant decrease in the percentage of NRP1-positive cells among lymphocytes was found in rejected kidney graft biopsies, which might point to a potential role of NRP1 in predicting the immune state of kidney grafts as a marker of regulatory $\mathrm{T}$ cells. ${ }^{33}$ Very recently it has been shown that advanced glycation end-products suppress NRP1 expression in mouse podocytes and that NRP1 expression is decreased in glomeruli of diabetic $d b / d b$ mice when compared with their nondiabetic littermates. ${ }^{7}$ Finally, transcripts of both NRPs were found to be decreased in renal biopsies from patients with diabetic nephropathy when compared with transplant donors. ${ }^{7}$ Here, we report the upregulation of tubular and interstitial NRP2, but not of NRP1 expression in human FSGS, suggesting for the first time a differential role of the two NRP isoforms in tubulointerstitial fibrogenesis. This idea is further supported by our observed effects of
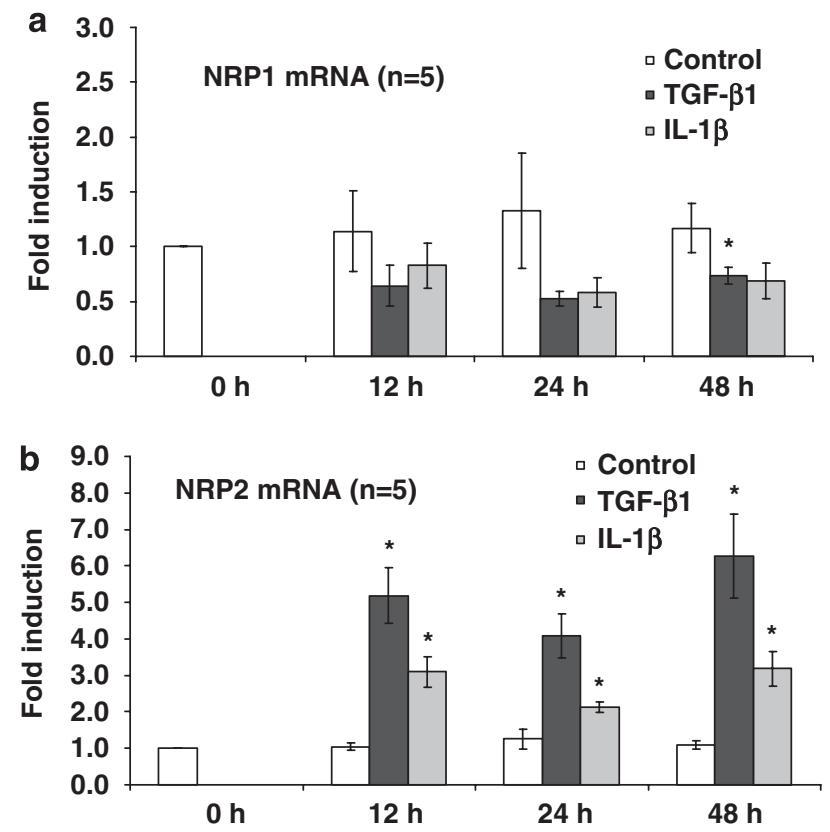

C $\quad \begin{array}{llllllllllllll}0 & 1 & 3 & 6 & 12 & 24 & 48 & 1 & 3 & 6 & 12 & 24 & 48 & h\end{array}$

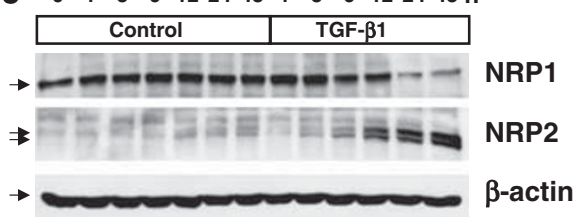

Figure 5 Time-dependent effects of TGF- $\beta 1$ and IL-1 $\beta$ on the expression of NRP1 and NRP2 in human PTC. Cells were serum- and supplement-starved for $48 \mathrm{~h}$, and were then stimulated with $10 \mathrm{ng} / \mathrm{ml} \mathrm{TGF-} \beta 1$ or $10 \mathrm{ng} / \mathrm{ml} \mathrm{IL-} 1 \beta$ for the indicated periods of time. (a) Time course of TGF- $\beta 1$ - and IL-1 $\beta$ mediated effects on NRP1 mRNA expression in human PTC $\left({ }^{*} P<0.05\right.$ compared with the respective time control). (b) Time course of TGF- $\beta 1$ - and IL-1 $\beta$-mediated effects on NRP2 mRNA expression in human PTC $\left({ }^{*} P<0.01\right.$ compared with the respective time controls). cDNAs from $n=5$ independent RNA isolations were applied for real-time PCR analysis. Data are presented as fold induction above NRP1 and NRP2 mRNA control levels after normalizing to GAPDH expression. Each data point indicates the average of five independent experiments with error bars corresponding to s.e.m. (c) Time course of TGF- $\beta 1$-mediated effects on NRP1, NRP2 and $\beta$-actin protein expression in human PTC. Protein-matched samples of stimulated cells and unstimulated controls were separated on SDS-PAGE and analyzed by western immunoblot for protein expression of NRP1, NRP2, and $\beta$-actin. The results from one representative western blot of $n=3$ separate experiments are depicted.

the two cytokines, TGF- $\beta 1$ and IL-1 $\beta$, on NRP1 and NRP2 expression in human PTC. It is widely accepted that TGF- $\beta 1$ and its downstream signaling has an essential role in tissue fibrosis in general and in renal fibrosis in particular. Besides that TGF- $\beta 1$ and IL- $1 \beta$ also represent well established stimulators of renal tubular EMT, a phenotypic conversion of mature tubular epithelial cells towards (myo)fibroblasts that is fundamentally linked to the pathogenesis of renal interstitial fibrosis. ${ }^{11-13}$ Hence these ligands, together with other cytokines such as platelet-derived growth factor or fibroblast 

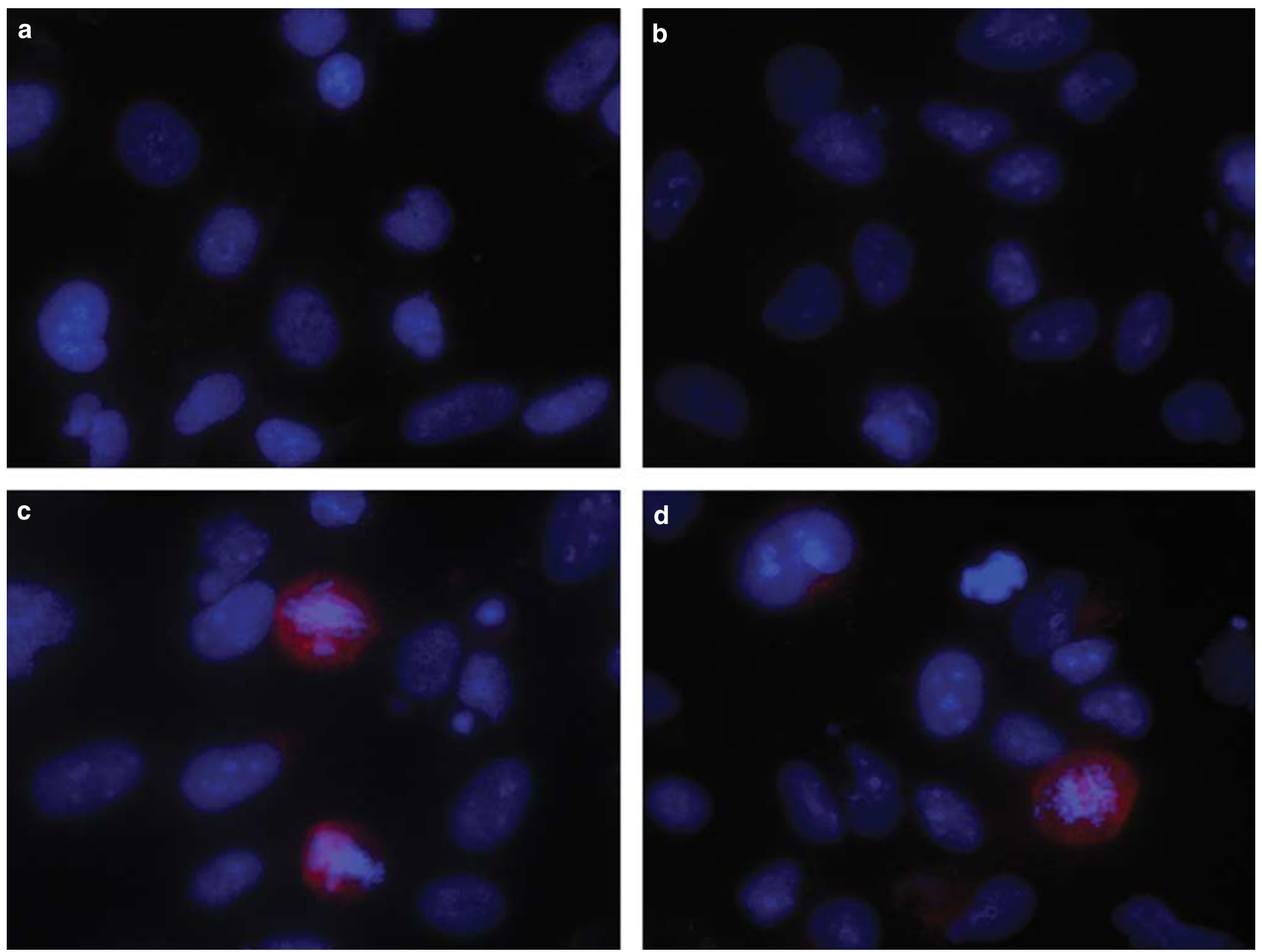

Figure 6 Indirect immunofluorescence stainings for NRP1 and NRP2 in human PTC. Serum- and supplement-starved cells were stimulated with $10 \mathrm{ng} / \mathrm{ml} \mathrm{TGF}-\beta 1$ for 24,48 , and $72 \mathrm{~h}$ and compared with unstimulated controls. (a) NRP2 was not detectable under basal conditions. (b) Stimulation of cells with TGF- $\beta 1$ for up to $72 \mathrm{~h}$ resulted in no detectable NRP1 expression. Conversely, NRP2 expression was inducible in selected tubular epithelial cells as early as $24 \mathrm{~h}$ after stimulation with TGF- $\beta 1$ peaking after $48 \mathrm{~h}$ (c) and $72 \mathrm{~h}$ (d). Most (but not all) of the NRP2 positive cells were undergoing mitosis. In order to identify cells, nuclei were counterstained with DAPI. All magnifications $\times 1000$.

growth factor2 (FGF2), may differentially affect NRP isoform expression leading to fibroblast generation, activation, and subsequent accumulation of ECM proteins resulting in tubulointerstitial fibrosis. In endothelial and various cancer cells, however, growth factors and cytokines, such as EGF, FGF2, VEGF, and TNF- $\alpha$, have been reported to stimulate NRP1 expression. ${ }^{34-40}$ In contrast, no stimulators of NRP2 expression have been published so far. ${ }^{3,26}$ As additional mechanisms that favor the maintenance of an epithelial architecture, such as those driving MET, must exist in a healthy renal proximal tubular system, even in response to tubular injury, cellular mechanisms acting in both directions might be turned on. ${ }^{10}$ Indeed, it has been speculated that OSM may represent a cytokine that has the ability to act as both a pro-EMT molecule and a pro-MET mediator depending on the tubular epithelial cell microenvironment and/or the specific injury. ${ }^{10}$ In this context, it is of interest that the IL-6 family member OSM stimulates both NRP1 and NRP2 expression in human PTC, in contrast to the two established pro-fibrotic mediators, TGF- $\beta 1$ and IL- $1 \beta$. Both OSM-induced NRP1 expression and TGF- $\beta 1$-induced NRP2 expression seem to be partially mediated by MEK1/2-ERK $1 / 2$ signaling. Indeed, major signal transduction pathways that induce EMT include Smad signaling, PI3K, the mitogenactivated protein kinases ERK1/2, and STAT signaling. ${ }^{18,41}$ Especially in the renal tubular system, strong evidence exists for an important function of the MEK1/2-ERK1/2 signaling module in EMT. ${ }^{10,42-44}$ Furthermore, it has been reported that OSM represents a strong stimulator of both ERK1/2 and STAT1/3 signaling in human PTC. ${ }^{10}$

In summary, the final functional cellular outcome of differential NRP isoform expression in renal cells such as tubular epithelial cells or tubulointerstitial fibroblasts could be controlled by gradients of extracellular ligands, by coexpression of signaling receptors, such as plexins or VEGFRs, and by ligands acting through NRPs and their co-receptors. 

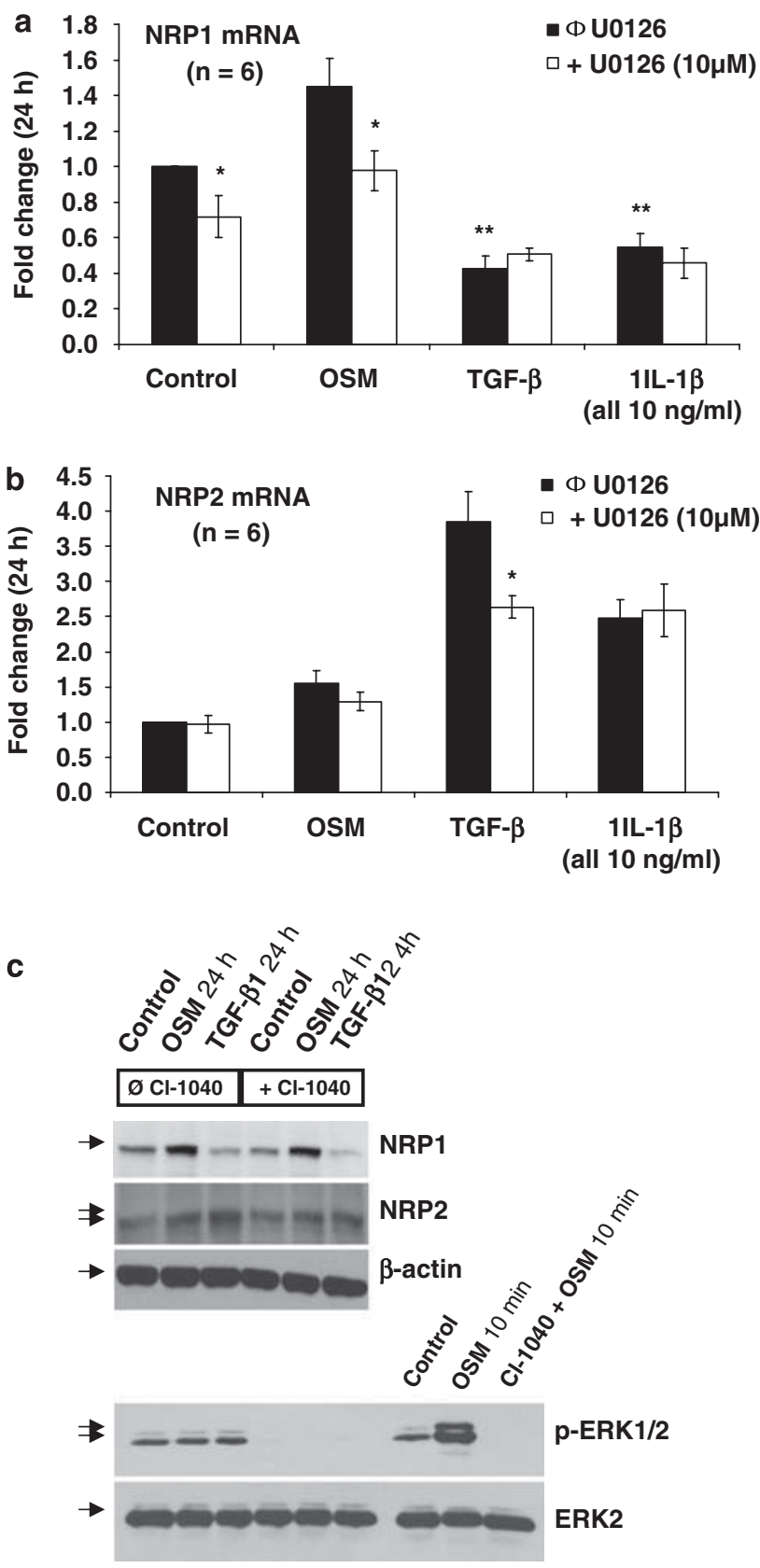

For example, some SEMAs such as SEMA3F have been reported to function as anti-tumorigenic and anti-angiogenic agents, whereas others such as SEMA4D have pro-angiogenic and pro-tumorigenic effects. ${ }^{45}$ Moreover, one has to keep in mind that NRP1 isoform expression might follow a different time course when compared with NRP2. We believe that our data derived from this in vivo and in vitro experiments establish an involvement of NRP1 and NRP2 in renal tubulointerstitial pathophysiology. All together, it is tempting to speculate that, depending on the renal cellular microenvironment and on their relative amount of expression, these two co-receptors may contribute to either renal fibrogenesis or tubulointerstitial protection and repair
Figure 7 Cytokine-mediated effects on NRP1 and NRP2 expression in the absence and in the presence of the synthetic MEK1/2 inhibitors U0126 and $\mathrm{Cl}-1040$. ( $\mathbf{a}$ and $\mathbf{b}$ ) Real-time PCR analysis of NRP1 and NRP2 mRNA expression in human PTC, which were serum- and supplement-starved for $48 \mathrm{~h}$, and which were then stimulated for $24 \mathrm{~h}$ with $10 \mathrm{ng} / \mathrm{ml}$ of OSM, TGF- $\beta 1$, or IL-1 $\beta$ either in the absence ( $\varnothing$ U0126) or in the presence ( + U0126) of $10 \mu \mathrm{M}$ U0126. CDNAs from $n=6$ independent RNA isolations were used for real-time PCR analysis of the NRP1 gene (a) and the NRP2 gene (b), respectively. Data are presented as fold induction above NRP1 or NRP2 mRNA control levels after normalizing to GAPDH expression. Each data point indicates the average of six independent experiments with error bars corresponding to s.e.m. (a) ${ }^{*} P<0.05$ compared with unstimulated or OSM-stimulated cells in the absence of U0126. TGF- $\beta 1$ and IL-1 $\beta$ led to a significant inhibition of NRP1 mRNA expression. ( $* * P<0.001$ compared with unstimulated control cells). (b) $* P<0.01$ compared with TGF- $\beta 1$-stimulated cells in the absence of U0126. (c) Western blot analysis of NRP1, NRP2, ERK2 protein expression, and of ERK $1 / 2$ phosphorylation in human PTC, which were serum- and supplement-starved for $48 \mathrm{~h}$, and were then stimulated with OSM $(10 \mathrm{ng} / \mathrm{ml})$ or TGF- $\beta 1(10 \mathrm{ng} / \mathrm{ml})$ for $24 \mathrm{~h}$ either in the absence $(\varnothing \mathrm{Cl}-1040)$ or in the presence $(+\mathrm{Cl}-1040)$ of the synthetic MEK $1 / 2$ inhibitor $\mathrm{Cl}-1040(1 \mu \mathrm{M})$. As an additional, positive control human PTC were stimulated for $10 \mathrm{~min}$ with OSM in the absence and in the presence of Cl-1040 (PD184352). Protein-matched samples of whole cell lysates (for NRP1, NRP2, $\beta$-actin) and soluble lysates (for $\mathrm{p}$-ERK1/2 and ERK2) were separated on SDS-PAGE and analyzed by western immunoblot for protein expression of NRP1, NRP2, $\beta$-actin, phosphorylated-ERK1/2 (p-ERK1/2), and ERK2. The results from one representative western blot of $n=4$ independent experiments are depicted.

processes. If this were so, then therapeutically targeting NRP isoforms may offer a novel approach to the inhibition of pathophysiological mechanisms associated with tubulointerstitial fibrogenesis.

\section{ACKNOWLEDGEMENT}

This work was supported by the Austrian National Bank (Grant No. 12221 to $\mathrm{HS})$.

\section{DISCLOSURE/CONFLICT OF INTEREST}

The authors declare no conflict of interest.

1. Gagnon ML, Bielenberg DR, Grechtman $Z$, et al. Identification of a natural soluble neuropilin-1 that binds vascular endothelial growth factor: in vivo expression and antitumor activity. Proc Natl Acad Sci USA 2000;97:2573-2578.

2. Klagsbrun $M$, Takashima S, Mamluk R. The role of neuropilin in vascular and tumor biology. Adv Exp Med Biol 2002;515:33-48.

3. Bielenberg DR, Pettaway CA, Takashima $S$, et al. Neuropilins in neoplasms: expression, regulation, and function. Exp Cell Res 2006;312:584-593.

4. Gray MJ, Van Buren G, Dallas NA, et al. Therapeutic targeting of neuropilin-2 on colorectal carcinoma cells implanted in the murine liver. J Natl Cancer Inst 2008;100:109-120.

5. Harper SJ, Xing CY, Whittle C, et al. Expression of neuropilin-1 by human glomerular epithelial cells in vito and in vivo. Clin Sci 2001;101:439-446.

6. Karihaloo A, Karumanchi SA, Cantley WL, et al. Vascular endothelial growth factor induces branching morphogenesis/tubulogenesis in renal epithelial cells in a neuropilin-dependent fashion. Mol Cell Biol 2005;25:7441-7448.

7. Bondeva $T$, Rüster $C$, Franke $S$, et al. Advanced glycation end-products suppress neuropilin-1 expression in podocytes. Kidney Int 2009;75:605-616. 
8. Ryan MJ, Johnson G, Kirk J, et al. HK-2: an immortalized proximal tubule epithelial cell line from normal adult human kidney. Kidney Int 1994;45:48-57.

9. Sarközi R, Miller B, Pollack V, et al. ERK1/2-driven and MKP-mediated inhibition of EGF-induced ERK5 signaling in human proximal tubular cells. J Cell Physiol 2007;211:88-100.

10. Pollack V, Sarközi R, Banki Z, et al. Oncostatin M-induced effects on EMT in human proximal tubular cells: differential role of ERK signaling. Am J Physiol Renal Physiol 2007;293:F1714-F1726.

11. Liu Y. Epithelial to mesenchymal transition in renal fibrogenesis: pathologic significance, molecular mechanisms, and therapeutic intervention. J Am Soc Nephrol 2004;15:1-12.

12. Neilson EG. Mechanisms of disease: fibroblasts-a new look at an old problem. Nat Clin Pract Nephrol 2006;2:101-108.

13. Strutz F, Zeisberg M. Renal fibroblasts and myofibroblasts in chronic kidney disease. J Am Soc Nephrol 2006;17:2992-2998.

14. Liu Y. Renal fibrosis: new insights into the pathogenesis and therapeutics. Kidney Int 2006;69:213-217.

15. Fan JM, Huang XR, Ng YY, et al. Interleukin-1 induces tubular epithelialmyofibroblast transdifferentiation through a transforming growth factor-beta1-dependent mechanism in vitro. Am J Kidney Dis 2001;37:820-831.

16. Bierie B, Moses HL. TGF $\beta$ : the molecular Jekyll and Hyde of cancer. Nat Rev Cancer 2006;6:506-520.

17. Zavadil J, Böttinger EP. TGF- $\beta$ and epithelial-to-mesenchymal transitions. Oncogene 2005;24:5764-5774.

18. Li M-X, Liu B-C. Epithelial to mesenchymal transition in the progression of tubulointerstitial fibrosis. Chin Med J 2007;120:1925-1930.

19. Takagi S, Tsuji T, Amagai T, et al. Specific cell surface labels in the visua centers of Xenopus laevis tadpole identified using monoclonal antibodies. Dev Biol 1987;122:90-100.

20. Kawasaki T, Kitsukawa T, Bekku $Y$, et al. A requirement for neuropilin-1 in embryonic vessel formation. Development 1999;126:4895-4902.

21. Gu C, Rodriguez ER, Reimert DV, et al. Neuropilin-1 conveys semaphorin and VEGF signaling during neural and cardiovascular development. Dev Cell 2003;5:45-57.

22. Kitsukawa T, Shimizu M, Sanbo M, et al. Neuropilin-semaphorin III/Dmediated chemorepulsive signals play a crucial role in peripheral nerve projection in mice. Neuron 1997;19:995-1005.

23. Lee $P$, Goishi $K$, Davidson AJ, et al. Neuropilin-1 is required for vascular development and is a mediator of VEGF-dependent angiogenesis in zebrafish. Proc Natl Acad Sci USA 2002;99:10470-10475.

24. Pan Q, Chanthery Y, Liang WC, et al. Blocking neuropilin-1 function has an additive effect with anti-VEGF to inhibit tumor growth. Cancer Cell 2007;11:53-67.

25. Guttmann-Raviv N, Kessler O, Shraga-Heled N, et al. The neuropilins and their role in tumorigenesis and tumor progression. Cancer Lett 2006;231:1-11.

26. Staton CA, Kumar I, Reed MWR, et al. Neuropilins in physiological and pathological angiogenesis. J Pathol 2007;212:237-248.

27. Pellet-Many $C$, Frankel $P$, Jia $H$, et al. Neuropilins: structure, function and role in disease. Biochem J 2008;411:211-226.

28. Latil A, Bièche I, Pesche $S$, et al. VEGF overexpression in clinically localized prostate tumors and neuropilin-1 overexpression in metastatic forms. Int J Cancer 2000;89:167-171.
29. Hansel DE, Wilentz RE, Yeo CJ, et al. Expression of neuropilin-1 in highgrade dysplasia, invasive cancer, and metastases of the human gastrointestinal tract. Am J Surg Pathol 2004;28:347-356.

30. Kawakami T, Tokunaga T, Hatanaka H, et al. Neuropilin 1 and neuropilin 2 co-expression is significantly correlated with increased vascularity and poor prognosis in nonsmall cell lung carcinoma. Cancer 2002;95:2196-2201.

31. Gray MJ, Wey JS, Belcheva A, et al. Neuropilin-1 suppresses tumorigenic properties in a human pancreatic adenocarcinoma cell line lacking neuropilin-1 coreceptors. Cancer Res 2005;65:3664-3670.

32. Villegas $G$, Tufro A. Ontogeny of semaphorins $3 A$ and $3 F$ and their receptors neuropilins 1 and 2 in the kidney. Mech Dev 2002;119S:S149-S153.

33. Zhou $H$, Zhang $L$, Tong $L$, et al. Expression of neuropilin-1 in kidney graft biopsies: what is the significance? Transplant Proc 2007;39:81-83.

34. Oh $\mathrm{H}$, Takagi $\mathrm{H}$, Otani $\mathrm{A}$, et al. Selective induction of neuropilin-1 by vascular endothelial growth factor (VEGF): a mechanism contributing to VEGF-induced angiogenesis. Proc Natl Acad Sci USA 2002;99:383-388.

35. Giraudo $E$, Primo $L$, Audero $E$, et al. Tumor necrosis factor-alpha regulates expression of vascular endothelial growth factor receptor-2 and of its co-receptor neuropilin-1 in human vascular endothelial cells. J Biol Chem 1998;273:22128-22135.

36. Akagi M, Kawaguchi M, Liu W, et al. Induction of neuropilin-1 and vascular endothelial growth factor by epidermal growth factor in human gastric cancer cells. Br J Cancer 2003;88:796-802.

37. Parikh AA, Fan F, Liu WB, et al. Neuropilin-1 in human colon cancer: expression, regulation, and role in induction of angiogenesis. Am J Pathol 2004;164:2139-2151.

38. Parikh AA, Liu WB, Fan F, et al. Expression and regulation of the novel vascular endothelial growth factor receptor neuropilin-1 by epidermal growth factor in human pancreatic carcinoma. Cancer 2003;98:720-729.

39. Liu W, Parikh AA, Stoeltzing O, et al. Upregulation of neuropilin-1 by basic fibroblast growth factor enhances vascular smooth muscle cell migration in response to VEGF. Cytokine 2005;32:206-212.

40. Yang $\mathrm{H}$, Li $\mathrm{M}$, Chai $\mathrm{H}$, et al. Expression and regulation of neuropilins and VEGF receptors by TNF- $\alpha$ in human endothelial cells. J Surg Res 2004;122:249-255.

41. Moustakas A, Heldin C-H. Signaling networks guiding epithelialmesenchymal transitions during embryogenesis and cancer progression. Cancer Sci 2007;98:1512-1520.

42. Schramek H, Feifel E, Healy E, et al. Constitutively active mutant of the mitogen-activated protein kinase kinase MEK1 induces epithelial dedifferentiation and growth inhibition in Madin-Darby Canine Kidney-C7 cells. J Biol Chem 1997;272:11426-11433.

43. Montesano R, Soriano JV, Hosseini G, et al. Constitutively active mitogen-activated protein kinase kinase MEK1 disrupts morphogenesis and induces an invasive phenotype in Madin-Darby Canine Kidney epithelial cells. Cell Growth Diff 1999;10:317-332.

44. Schramek H, Feifel E, Marschitz l, et al. Loss of active MEK1-ERK1/2 restores epithelial phenotype and morphogenesis in transdifferentiated MDCK cells. Am J Physiol Cell Physiol 2003;285:C652-C661.

45. Neufeld G, Kessler O. The semaphorins: versatile regulators of tumour progression and tumour angiogenesis. Nature Rev Cancer 2008;8:632-645. 